Rev. Latinoam. Psicopat. Fund., São Paulo, v. 14, n. 3, p. 542-562, setembro 2011

\title{
Alucinações táteis: aspectos conceituais e históricos*
}

\author{
German E. Berrios
}

Uma breve análise histórica do conceito geral de alucinação é apresentada e sugere-se que ela surgiu como a generalização injustificada de um modelo perceptual que estava destinado a ser aplicado apenas para a visão e os "sentidos de distância". Neste contexto, considera-se a evolução das alucinações táteis e explorase sua interação com a teoria psicológica vigente no século XIX. Conclui-se que as alucinações táteis são fenômenos sui generis que não se encaixam no modelo convencional e que a identificação de seu quadro clínico baseia-se, até o momento, em critérios pouco claros. Apresenta-se uma breve revisão da sua taxonomia e utilidade diagnóstica. Algumas implicações mais amplas são delineadas, as quais podem ser relevantes para a concepção geral da alucinação.

Palavras-chave: Alucinações táteis, psicopatologia do tato, alucinações - história, alucinações - diagnóstico

* Publicação original: Tactile hallucinations: conceptual and historical aspects. Journal of Neurology, Neurosurgery, and Psychiatry, n. 45, p. 285-293, 1982. Tradução de Lazslo A. Ávila, revisão técnica de Ana Maria G. R. Oda. 
A psicopatologia do tato, embora rica e complexa, tornou-se subordinada, na psiquiatria atual, a outros sintomas, e não atrai mais interesse descritivo ou diagnóstico. Isso tanto pode refletir a sua frequência clínica relativamente pequena como um mal-estar secular quanto ao seu estatuto conceitual.

O tato tem sido considerado, desde a época dos gregos, um relutante "quinto sentido". Aristóteles (1968) considerou-o um sistema perceptivo primitivo $(1968,423 . b .12)$ e comentou sobre a característica fundamental que distingue o tato dos "sentidos de distância": "Mas há uma diferença entre o objeto do tato e aqueles da visão e audição, já que percebemos a esses porque o meio age sobre nós, enquanto percebemos objetos do tato não através do agenciamento do meio, mas simultaneamente com o meio, como um homem que é atingido pelo seu escudo" (1968, 423.b.12).

Essa visão permaneceu inalterada até o século XVII, quando o empirismo britânico desenvolveu um interesse pela epistemologia do tato. Locke (1959) por exemplo, rejeitou a visão cartesiana, de acordo com a qual a extensão constituiria a essência da substância material. Além da extensão ele afirmou que todos os corpos possuem a qualidade fundamental da "solidez". Portanto, reconheceu a "solidez" como "a ideia mais intimamente ligada com e essencial ao corpo, a ser encontrada ou imaginada em nenhum outro lugar, mas apenas na matéria" (1959, II, IV, 1). Esta ideia "nós recebemos pelo nosso tato, e surge a partir da resistência que encontramos no corpo para a entrada de qualquer outro corpo no espaço que ele ocupa, até que o deixe" (1959, II, IV, 1).

A investigação epistemológica sobre quais são os componentes corporais que sugerem a ideia de solidez levou à identificação de "sentimentos 
de resistência" e "sensações motoras" que transmitiam informações superiores para os "meros sentimentos". Armstrong (1962) expressou isso assim: "Para todas as formas de percepção sensorial além da visão, audição, paladar e olfato empregamos a palavra 'sentir': no entanto, será conveniente fazer a distinção entre pelo menos dois tipos de percepção sensorial abrangidas pela palavra 'sentir': a percepção através do tato e a percepção de nosso próprio estado corporal”. Esta distinção foi introduzida na Psicologia por Weber (1846) como Tastsinn (tato) e Gemeingefuihl (sensibilidade comum). Estas duas categorias proveram os psiquiatras do final do século XIX com uma estrutura conceitual para descrever e classificar fenômenos clínicos tão amplamente distanciados como as alucinações táteis, a neurastenia, a cenestopatia e a despersonalização.

\section{O problema geral}

O atual modelo conceitual da alucinação foi desenvolvido durante o início do século XIX sem a análise da visão. Dos casos originais relatados por Esquirol (1938), cinco tinham alucinações visuais. Ele iniciou seu trabalho afirmando: "Se um homem tem a convicção íntima de realmente perceber uma sensação para a qual não há objeto externo, ele está em um estado alucinado: ele é um visionário (visionnaire)"; e concluiu: "As alucinações de visão ... foram chamadas de visões, mas este termo é apropriado apenas para um modo de percepção. Quem se atreve a falar de visões auditivas, visões gustativas, visões olfativas? ... Mas as alterações funcionais, mecanismos cerebrais e o contexto clínicos envolvidos nestes três sentidos é o mesmo que nas visões (meu itálico). Um termo genérico é necessário. Propus a palavra alucinação..." Este tratamento homogêneo de todas as modalidades de sentido supõe que elas se comportam conceitualmente de maneira simétrica, por exemplo, que obedecem ao paradigma "causalista" (isto é requerido para um "externo objeto" se impor sobre os sensores os sentidos). Este ponto de vista Esquirol recebeu de Condillac (1754). Portanto, ao generalizar a definição de alucinação como uma "percepção sem objeto", ele incorporou como uma exigência lógica a ausência de um objeto externo e público.

Essa epistemologia simétrica tem-se mantido consagrada na psicopatologia fenomenológica que herdamos do século XIX. Ela não faz distinção entre, por um lado, a visão, a audição e olfato, que têm um "objeto" no espaço público (cujo estatuto existencial pode ser consensualmente determinado) e, por outro, as restantes sensações corporais, a algumas das quais o modelo clássico não parece aplicar-se.

Rev. Latinoam. Psicopat. Fund., São Paulo, v. 14, n. 3, p. 542-562, setembro 2011 
Calor, pressão e vibração, em circunstâncias comuns, parecem estar relacionados com agências externas e, portanto, estão abertos à avaliação consensual, pois podem ser considerados ajustados ao modelo "causal". Mas sensações tais como dores, coceiras, espasmos, cócegas etc., dependem, essencialmente, de serem "sentidas" e sua realidade, portanto, não está logicamente conectada agentes externos; daí o relato do sujeito em circunstâncias normais será aceito sem contestação.

Os critérios atuais para verificar a presença de alucinações na prática clínica são complexos e ainda não foram completamente solucionados na literatura. Características tais como bizarrice de conteúdo e de contexto, o estado cognitivo concomitante, os sinais comportamentais, a ausência do objeto externo, podem ser todos importantes. Teoricamente este último parece crucial, uma vez que segue logicamente a partir da própria definição de alucinação como uma "percepção sem objeto". Se esse fosse o caso, como se aplicaria à alucinação tátil? Como uma coceira real pode ser distinguida de uma alucinada se em nenhum dos casos é necessária a presença de um objeto no espaço público? São, talvez, as alucinações de tato diferentes em um modo fundamental daquelas que ocorrem nos "sentidos de distância"?

Esta distinção abstrata pode ou não ser clinicamente relevante. Por exemplo, pode-se dizer que o critério do "objeto externo" não é importante para o diagnóstico das alucinações táteis. Na verdade, pode-se dizer que não é importante para o diagnóstico das alucinações visuais ou auditivas em geral. Este seria baseado na observação de que normalmente os psiquiatras não procuram o objeto alucinado no espaço público. É sobre as bases dos sintomas concomitantes, do contexto, da história passada e da qualidade das experiências alucinatórias relatadas que o diagnóstico geralmente é feito. Se este for o caso, então segue-se que os aspectos "perceptuais" das alucinações podem não ser, afinal, tão importantes.

Desde o século XIX, conceitos relacionados à percepção têm sido usados em dois planos em relação às alucinações: (1) de forma descritiva, como quando os relatos dos pacientes sobre o "ver" ou "ouvir" coisas são tomados em seu valor de face e registrados como "dados perceptuais sem necessariamente ter uma base na realidade"; (2) etiologicamente, como quando conclui-se que devido ao tipo de experiências os pacientes em causa estão, na verdade, sofrendo de um "distúrbio da percepção". O primeiro plano é neutro em termos teóricos, no sentido de que os relatos dos pacientes podem ser tomados como significando apenas que eles "acreditam" que sua percepção esteja envolvida, não comprometendo o observador a supor que a percepção esteja "realmente" perturbada (Esquirol tomou esta linha). O segundo plano, no entanto, compromete o psiquiatra a analisar o aparato perceptivo do paciente, pois supõe que o hardware perceptual esteja efetivamente prejudicado. 


\section{Contexto histórico}

A visão de que todos os tipos de alucinações são fundamentalmente distúrbios de percepção foi predominante desde o início do século XIX. A distinção entre as alucinações "orgânicas" e "funcionais" iniciou-se em 1850 e criou tantos problemas quantos solucionou. Originou-se da confluência das duas psicologias reinantes durante este período: enquanto o associacionismo sustentava a análise das experiências mentais em unidades discretas, a psicologia das faculdades mentais assegurava a autonomia da percepção.

Por exemplo, a noção de "pseudoalucinação" foi utilizada desde Hagen até Kandinsky (Rokhline, 1971) para lidar com as anomalias clínicas que não se encaixavam nem nas categorias orgânicas e nem nas funcionais. É lamentável que a interpretação idiossincrática de Kandinsky feita por Jaspers (1963) tenha levado à visão oficial de que as pseudoalucinações constituissem uma "terceira" classe. Esta anacrônica conclusão ignora o fato de que Kandinsky escreveu no contexto de um debate em curso sobre as alucinações e que sua intenção era fornecer um receptáculo para experiências alucinatórias inclassificáveis. Seja como for, os chamados critérios definidores para as pseudoalucinações não se aplicam ao sentido do tato, para os quais as questões de percepção e espaço externo não contam. A concepção da alucinação como um transtorno simétrico e homogêneo em todos os cinco sentidos se choca com a impossibilidade de "pseudoalucinações" ocorrerem em alguma das modalidades do sentido (ou seja, o tato).

Desde o século XIX as psiquiatrias nacionais responderam a essas dificuldades de acordo com as filosofias e etimologias locais. Por exemplo as psiquiatrias francesa e alemã têm estabelecido uma linha divisória menos rigorosa entre as alucinações e os delírios do que a psiquiatria inglesa. Délire e Wahn (termos francês e alemão para o delírio, respectivamente) têm uma orientação menos "intelectualista" do que o termo inglês (Berrios, 1981). Além disso, eles pressupõem um distúrbio de personalidade e uma fratura no "relacionamento" entre o sujeito e seu mundo que falta no termo inglês delusion, normalmente definido como "crença" errada ou patológica, isto é, como um distúrbio do pensamento. As alucinações, portanto, tendem a ser consideradas na psiquiatria continental um subtipo dos delírios (isto é, "delírios sensoriais") e menor ênfase, portanto, é colocada sobre seus aspectos de "percepção" do que sobre os aspectos "cognitivos" ou de "apercepção" (Scharfetter, 1976; Ey, 1973). Em oposição a isso, a visão "intelectualista" da loucura que Locke endossou ainda é reconhecível nas perspectivas britânicas tanto do delírio quanto da alucinação. 


\section{Alucinações táteis}

Os livros sobre psicopatologia descritiva são singularmente reticentes quanto à alucinação tátil (Parish, 1897; West, 1962; Keup, 1970; Siegel, 1975; Johnson, 1978) e o Traité de Ey dedica-lhe apenas 16 páginas (de um total de 1543). Isso pode refletir a sua pouca importância clínica e estatística, mas também sua confusa condição conceitual. Descrições de "coceiras imaginárias" são encontradas na literatura antecedente. Darwin $(17$ 1796) relatou o caso de um indivíduo com diabetes imaginária que experimentava "uma ideia alucinada (uma coceira) tão poderosamente excitada que não era possível ser alterada de repente, pelo sentido visual ou pela razão". Durante o século XIX, descrições clínicas de alucinações táteis são encontradas associadas a quatro áreas clínicas: insanidade; experiências somáticas anormais não psicóticas complexas (cenestopatias, por exemplo); síndromes orgânicas e tóxicas e o conceito em desenvolvimento de "parasitose delirante".

\section{As alucinações táteis e as insanidades}

Esquirol (1938) em uma veia lockeana escreveu: “o tato, muitas vezes chamado pela razão para corrigir os outros sentidos, pode também enganar o insano ..., pode alucinar superfícies ásperas ou extremidades afiadas ferindo sua pele, pode sentir-se dilacerado por instrumentos de corte". Sigmond (1848) observou que "alucinações do tato variam muito; é muito singular encontrar um indivíduo que acredita que têm ratos rastejando sobre ele, ou que aranhas o infestam...". Griesinger (1867) fez a observação fundamental de que no tato "as alucinações e delírios não podem ser distinguidos uns dos outros, ou melhor, de que os fenômenos que os constituem, na medida em que não dependem de anestesia, devem em todos os casos ser considerados delírios, porque a anomalia específica consiste na falsa interpretação de certas sensações" (grifo meu).

Brierre de Boismont (1859) afirmou: "diz-se que as alucinações do tato são difíceis de investigar porque elas tendem a ser confundidas com doenças neurológicas... não pode haver dúvidas de que existem algumas pessoas alucinadas perfeitamente capazes de julgar corretamente suas sensações". Brierre, portanto, acreditava que ao exame físico não havia nada neurologicamente de errado com os pacientes que experimentavam alucinações táteis. Tuke (1892) não separava as alucinações táteis das alucinações internas ou corporais e incluía na rubrica "experiências alucinatórias táteis" experiências tais como "choque elétrico", "delírio de ser transformado ou licantropia" e "alucinações sexuais". Störring

Rev. Latinoam. Psicopat. Fund., São Paulo, v. 14, n. 3, p. 542-562, setembro 2011 
( 1907) incluiu todos estes nas "alucinações do sentido cutâneo": "No delirium tremens os pacientes muitas vezes têm sensações alucinatórias de aranhas rastejando sobre a pele, de formigas correndo sobre eles ou de estarem cobertos por uma pele". Ele também incluiu experiências mais complexas: "Eles frequentemente queixam-se de correntes elétricas atravessando seus corpos. Outros se sentem como se estivessem sendo beijados, ou como se alguém estivesse deitado ao seu lado".

Ao escrever sobre "sensações táteis mórbidas" Kraepelin (1919) incluiu formigamento, experiências sexuais bizarras e vivências de movimento complexo envolvendo o corpo do paciente. Ele afirmou que: "não frequentemente nem sempre estas imaginações, ligadas aparentemente com sensações orgânicas, recebem uma interpretação muito estranha..." e "como resultado dessas alucinações frequentemente é desenvolvida nos pacientes a convicção que eles se tornaram o alvo de todos os tipos de influência". Bleuler (1950) separou cuidadosamente as alucinações corporais das táteis, dedicou uma longa seção para as primeiras e sobre as segundas escreveu: "alucinações táteis são raras (na esquizofrenia)... ocasionalmente, os pacientes queixam-se de pequenos animais, particularmente serpentes, rastejando sobre seus corpos".

\section{Alucinações táteis e cenestopatias}

Esta síndrome francesa (Dupré, 1913) reflete bem a anterior distinção conceitual alemã entre os sentidos da pele (Tastsinn) e a sensibilidade comum (Gemeingefühl) (Weber, 1846). Gemeingefühl refere-se às sensações corporais restantes, uma vez que aquelas associadas com a pele (isto é, o tato, a pressão, a temperatura e a localização) são consideradas separadamente. Elas constituem um conjunto heterogêneo, como a dor e as sensações "sem objeto", tais como o bem-estar, o prazer, a fadiga, o tremor, a fome, as náuseas, as sensações orgânicas etc. Este grupo também foi chamado cenestesia (Hamilton, 1859) e alguns profissionais especularam que elas forneciam ao sujeito que as experimentava o seu "sentido da existência" (Gautheret, 1961).

Para explicar a origem desta sensação corporal unificada, duas teorias foram propostas. $\mathrm{O}$ associacionismo afirmava que a cenestesia resultaria da soma das sensações proprioceptivas e interoceptivas (Taine, 1890); a psicologia das faculdades mentais, por outro lado, postulava a existência de um hipotético centro cerebral ou função sobre a qual convergiriam todas as sensações, com o resultante padrão somatognóstico consistindo em um tipo dinâmico de Gestalt que 
desse conta da posição do corpo no tempo. Ela forneceu a base no século XX para a noção do "esquema corporal".

Logo após o seu início, no entanto, o território psicológico da cenestesia sofreu erosão gradual, à medida que sensações como a fome, a sede, o prazer sexual etc. foram separadas. No final, tudo o que restava eram as sensações comuns a vários órgãos, tais como a pressão profunda, a dor ou sensações não analisáveis como "cócegas" ou "inchaço" (Titchener, 1901). Foi nessa fase que se desenvolveu o conceito de "cenestopatia" na psiquiatria francesa (Dupré, 1913). Foi definido como "alteração local da sensibilidade comum na esfera da sensação geral, correspondendo à alucinose na esfera do sensorium" (ibid.). Os tipos "doloroso" e "parestético" de cenestopatia foram reconhecidos e classificados como tendo cada um uma localização, cefálica, torácica ou abdominal. Pacientes do primeiro grupo podem sentir os seus órgãos sendo "esticados, rasgados, torcidos" etc., ou podem, no outro grupo, experimentar coceiras, hiperestesia, parestesia etc.

Esta síndrome nunca foi aceita na psiquiatria dos países anglo-saxões e os sintomas que se referiam a ela foram recatalogados como hipocondria, neurastenia ou dismorfofobia (Reilly, 1976). Na própria França, algumas cenestopatias, por exemplo a "topalgia" (ou cenestopatia cefálica) foram posteriormente incluídas em categorias alternativas de diagnóstico, tais como "distonias neurovegetativas" (Bernard, 1977), "distúrbios subjetivos da sensibilidade", associados a "psiconeuroses" (Ladee, 1966) ou simplesmente a síndromes psicossomáticas (Ey, 1950). Alguns psiquiatras franceses continuaram a estudar esses fenômenos sob a rubrica geral de "distúrbios do esquema corporal" (Bernard, 1977).

\section{Alucinações táteis e síndromes orgânicas e tóxicas}

Após o desenvolvimento da noção de "háptica" por Dessoir em 1892 (Titchener, 1901), o tato foi considerado cada vez menos um quinto sentido monolítico. Dessoir tinha dividido a háptica (que era para o tato o que a "ótica" era para a visão) em "sentido de contato" e "pselafesia", correspondentes, grosso modo, ao tato passivo e ativo, respectivamente. Movimento e "sensações motoras" foram identificados como caracterizando o tato ativo e forneceram a distinção conceitual crucial na classificação de Dessoir (Ziehen, 1909; Katz, 1925). Isso foi bem expresso por Merleau Ponty (1945): “o movimento do corpo é para o tato o que a luz é para a visão... Há fenômenos táteis, supostas qualidades táteis, como a aspereza e a suavidade, que desaparecem completamente se o movimento exploratório é eliminado". O tato ativo continua sendo tratado como uma categoria separada (Gordon, 1978).

Rev. Latinoam. Psicopat. Fund., São Paulo, v. 14, n. 3, p. 542-562, setembro 2011 
Experiências alucinatórias referentes ao tato ativo são clinicamente muito raras, mas ocasionalmente transformações sensoriais do tato ativo para a visão têm sido relatadas, como o caso de um paciente cego que alucinava visualmente em código Braille (Freeman, Williams, 1953). Alucinações táteis e, de fato, distorções táteis de todos os tipos (ou seja, alfinetes e agulhas) são, portanto, mais comuns no tato passivo. Isto foi reconhecido por Régis (1906): "alucinações no tato ativo são raras ... isto não acontece no tato passivo, onde se manifestam como sensações na pele tais como formigamento, esfregões, picadas, rastejamentos etc".

A parestesia e as coceiras podem ser relatadas direta ou obliquamente. Relatos diretos por indivíduos de outro ponto de vista normais tendem a ser considerados inquestionáveis e não resultantes de psicopatologia. Relatos oblíquos, por outro lado, fazendo uso de descrições analógicas "como se", podem ser encontrados em consultórios dermatológicos. Por razões que ainda estão obscuras, a qualificação "como se" pode, ocasionalmente, ser abandonada pelo paciente e substituída por uma interpretação delirante. Nestes casos, é mais provável que o psiquiatra intervenha. A história natural, incidência e mecanismos para estas transições são desconhecidos, embora sua existência clínica tenha sido observada há longo tempo. Griesinger (1867) em uma excelente descrição, escreve: "o início destes delírios consiste em certas sensações dolorosas sendo meramente comparadas fantasiosamente (grifo meu) pelo paciente com fenômenos análogos. Portanto, os hipocondríacos de início dizem apenas que parece como se serpentes se arrastassem por sua pele ... mas o prolongamento das sensações, a influência de circunstâncias externas desfavoráveis, uma crescente desarmonia interna ... os pacientes em breve começam a considerar o assunto mais intensamente, a comparação, a princípio imaginária, torna-se um delírio plenamente desenvolvido..."

Mas esse nem sempre é o caso. Em alguns casos a qualificação "como se" nunca é descartada e o atendimento hospitalar recorrente e os transtornos afetivos complicadores redefinem o problema como psiquiátrico. Em outros casos, a qualificação "como se" não está realmente presente, em vez disso o aspecto delirante aparece desde o início, com o componente alucinatório ou sensorial desempenhando um papel menor. Uma vez que a transição do "como se" ao delírio tiver tomado lugar, torna-se difícil separar a elaboração delirante da experiência sensorial bruta. É possível que a distorção cognitiva resultante do delírio possa agir como uma nova fonte de experiência; como ocorre, por exemplo, no chamado "fenômeno de simpatia", no qual um comichão (ou outras sensações) podem ser experimentados pelo observador na mesma área da pele onde ele acabara de testemunhar alguém se machucando. Daí ser possível que a persistente crença de ter insetos debaixo da pele (por exemplo, na parasitose delirante) possa gerar

Rev. Latinoam. Psicopat. Fund., São Paulo, v. 14, n. 3, p. 542-562, setembro 2011 
sensações na pele (ou mudanças nela) que por sua vez, confirmem e perpetuem a crença delirante.

O modelo para as alucinações táteis foi fornecido há mais de cem anos pelas experiências táteis que caracterizam o delirium tremens e a intoxicação por cocaína. O problema com o primeiro é que ele tende a ocorrer no contexto de consciência turvada e é composto por alucinações visuais e discretas interpretações delirantes. Alucinações "hápticas" por cocaína, por outro lado, podem ocorrer acompanhadas por consciência clara e isso as torna particularmente adequadas para a análise fenomenológica. Escritores clássicos também descreveram em detalhes as alucinações táteis devidas a cloral e a atropínicos.

Até $15 \%$ das pessoas que usam cocaína para "fins de lazer" podem relatar alucinações táteis (Siegel, 1978). No entanto, os indivíduos na amostra de Siegel consumiram pelo menos 1 grama de cocaína por mês durante 12 meses. A literatura inicial afirmava que é mais provável a cocaína injetável produzir alucinações táteis (Maier, 1928). Mais recentemente, tem sido relatado que ela também pode causar uma redução na sensibilidade tátil (Mortimer, 1974). Alucinações táteis podem aparecer após seis meses de uso persistente e na esteira de alucinações visuais. Sensações prodrômicas são a coceira nas mãos, pernas e costas; "coceiras deslocáveis" seguem-se acompanhadas por interpretações "como se" (por exemplo, "insetos" ou "pessoas escovando"). De acordo com Siegel,1978) nenhum de seus pacientes "acreditavam que insetos ou objetos estivessem realmente presentes, embora eles muitas vezes coçassem ou esfregassem a pele" (grifo meu). Ele concluiu, portanto, que essas experiências eram "pseudoalucinações".

Escritores clássicos, no entanto, as consideravam alucinações verdadeiras. Magnan e Saury (Magnan, Saury, 1889) descrevem como seus pacientes tentavam remover insetos de sob a pele. Clérambault (1909) elegantemente descreveu essas alucinações como hipodérmicas, distais e puntiformes, e acreditava que elas eram muitas vezes acompanhadas por "sensações de movimento" e pelo envolvimento da consciência. Alucinações táteis por cloral produzem sentimentos de "umidade" sobre a pele, mas não são acompanhadas de sensações "cinéticas". Em geral as alucinações por cloral são mais superficiais, acompanhadas por dor e sentidas nas dobras interdigitais (Ey, 1973). Alucinações táteis consequentes a intoxicação por Atropa belladona foram descritas por Moreau de Tours (1845) que relatou um caso que sentia "que milhões de insetos devoravam a sua cabeça".

Esses estados têm sido classicamente comparados à sensação de formigas caminhando sob a pele. Os termos genéricos cunhados para descrever essas sensações foram psora imaginária, "coceira imaginária" (Darwin, 1796) e formigamento. O último termo mencionado tinha sido utilizado em medicina geral pelo 
menos desde o século XVI, quando Ambroise Paré aproveitou de seu valor metafórico e descreveu o pouls formicant (pulso formigante) como "um pulso fraco frequente que dá a sensação de "rastejar como uma formiga"" (Littré, 1878). O mais antigo uso relatado em dermatologia ocorreu em 1707 (Oxford English Dictionary, 1971); por volta do século XIX, foi bem estabelecido não só em relação à intoxicação por cocaína, mas para qualquer condição em que "houvesse uma desagradável e insidiosa sensação na pele”.

Alucinações táteis associadas a outros estados orgânicos distintos dos que são induzidos por drogas também têm sido descritas na literatura, tais como a lesão cerebral (Ekbom, 1938); a demência (Harbauer, 1949; Bergman, 1957; Ganner, Lorenzi, 1975); o tumor hipofisário (Liebaldt, Klages, 1961); e o diabetes (Busch, 1960). Em sua amostra de 46 casos com delírios de infestação, Skott (1978) encontrou que cerca de 50\% apresentavam sinais clínicos de uma "síndrome cerebral orgânica"; $61 \%$ tinham EEGs patológicos e $12 \%$ tinham doenças malignas (por exemplo, carcinoma de mama, de colo, de cólon, de pulmão etc.). Berrios (observação não publicada) tem registrado um caso de alucinação tátil facial associado com tumor hipofisário e outro de parasitose delirante associada a linfoma mediastinal.

\section{Alucinações táteis e "parasitoses delirantes"}

Mulheres de meia-idade (ou mais velhas) sem história de intoxicação por drogas, ocasionalmente queixam-se de parasitas na ou sob a pele para agentes de saúde ou dermatologistas, e para psiquiatras com menor frequência. Insetos, vermes, percevejos ou outros animais pequenos não descritos vivem, procriam e fazem buracos na sua pele. Os pacientes, por vezes, podem datar o início disso para a época em que se mudaram para uma nova casa e muito raramente outros membros da família compartilham suas crenças. Os pacientes podem, por vezes também "ver" os insetos e produzem como prova de sua existência garrafas contendo pele, detritos, felpas etc.

Os aspectos clínicos e terapêuticos desta síndrome têm sido bem trabalhados na literatura recente e estão fora do escopo deste artigo (para uma revisão completa ver Skott, 1978). Hesitações conceituais, no entanto, pontuam a história da síndrome e ilustram bem as dificuldades envolvidas na própria noção de alucinação tátil. A descrição inicial da síndrome como "dermatoses de coceira pruriginosas" (Brocq, 1892); "acarofobia" (Thiebierge, 1894) e "parasitofobia" (Perrin, 1896) sugeriram, entre os autores posteriores, a impressão anacrônica de que a síndrome, ao final do século XIX, era realmente considerada como 
"fobia" ou "neurose". Contudo, o conceito de "fobia", naquele momento ainda não estava relacionado com as neuroses, na verdade estava apenas passando por uma transformação semântica para se separar das noções cognatas de obsessão e delírio. Essas três noções estavam contidas na fonte comum do conceito de "ideia fixa" que tinha sido usado por autores anteriores para se referir ao sintoma central da insanidade. Por exemplo, Perrin (1896) considera que sua "parasitofobia" seja generalizada, alucinatória, contínua e não acompanhada por ansiedade ou outras perturbações afetivas. Este escritor permaneceu indeciso quanto a qual era o transtorno primário nestes casos, dando início à confusão que até hoje caracteriza a interpretação desta síndrome. Por um lado, mencionou "profunda alteração das faculdades intelectuais" que se expressariam em uma "ideia fixa" (isto é, tendo uma origem delirante). Por outro, considerava as "alucinações" (isto é, as alterações sensoriais) cruciais para a síndrome.

Autores subsequentes desenvolveram alguma destas opções e os muitos nomes que eles criaram mostram suas preferências teóricas. Alguns acreditavam que o principal transtorno seria uma alucinação tátil ou ilusão (ou mesmo uma sensação real) com a interpretação delirante vindo em consequência (esse é o mecanismo que Griesinger sugeriu). MacNamara (1928) escreveu: "As alucinações ... constituem a sua mais notável característica". Mallet e Male (1930) em um frequentemente citado mas, inexpressivo artigo, consideraram as "alucinações hápticas" como o traço principal. Outros acharam que o componente de percepção era de fato primário, mas não necessariamente "alucinatório" em sua natureza. Por exemplo, Gamper (1931) sugeriu uma base orgânica para a coceira primária. Schwarz (1929) apontou que a síndrome pode se seguir a sensações anormais da pele, ocorrendo no início da doença depressiva. Ekbom (1938) acreditava que parestesia pré-senil estaria na base de sua Preseniler Dermatozoenwahn. Harbauer (1949), Fleck (1955), Liebaldt e Klages (1961), também apoiaram a ideia de que patologias primárias, orgânicas, sensoriais estariam na base da doença. Uma interpretação similar tem sido seguida em relação às alucinações visuais nos idosos, com alguns autores alegando que elas estão sempre associadas com as psicoses orgânicas ou funcionais ou com a catarata visual, e outros sustentando que elas podem ser o único sintoma presente (Berrios, Brook, 1982).

Em oposição a essa "perspectiva sensorialista" outros autores defenderam uma abordagem cognitiva, segundo a qual a síndrome seria primariamente delirante. Dupré descreveu um délire de zoopathie interne (delírio de zoopatia interna) e seu discípulo Levy a subdividiu em tipos "interno" e "externo" (Levy, 1906). A principal característica nestas síndromes seria a crença delirante (délire) de abrigar animais no ou sobre o corpo. Os 29 casos que ele descreveu envolviam ratos, pássaros, vermes, cobras etc., mas os insetos não são mencionados. Faure et a1. (1957), por sua vez, descreveram dois casos em que le délire zoopathique 
envolvia insetos e reiteraram a ideia de que o problema fundamental era "delirante" em sua natureza. Wilson e Miller (1946) sugeriram o termo "delírio de parasitose" e favoreceram a sua origem delirante; sua análise fenomenológica, porém, é insatisfatória. Alguns anos mais tarde, Wilson (1952) passou a afirmar que esses "delírios" poderiam até mesmo ocorrer nas "psiconeuroses".

Bers e Conrad (1954), em um artigo clássico, apresentam a noção de "alucinações táteis crônicas", mas tomam uma posição intermediária, pois consideram difícil decidir o que seria "primário" e o que seria "secundário". Esta hesitação, porém, deve ser entendida no contexto da visão "gestáltica" do Professor Conrad sobre os delírios (1958) e da história do conceito de "alucinoses" na psiquiatria alemã. Bers e Conrad sugeriram que um transtorno sensorial é, por vezes, relevante, mas pensavam que no geral a "alucinose tátil crônica" deveria estar baseada em um estado delirante, sendo esta, como qualquer outra alucinose crônica, acompanhada por alucinações que são análogas (Claude, Ey, 1932; Porot, 1975) àquelas que podem emergir nas personalidades com tendência a esquizofrenia (Conrad, 1960). Evidências de que a incidência da esquizofrenia pode ser maior em famílias de pacientes com parasitoses delirantes, no entanto, não se encontram disponíveis. Apesar disso, Skott (1978) descobriu que os irmãos de pacientes com delírios de infestação tem significativamente mais morbidade psiquiátrica do que os controles ( $p<0,01$ ). Se isso está ou não relacionado com a esquizofrenia não está especificado.

A posição britânica foi considerar estes estados de natureza fundamentalmente delirante (Reilly, Beard, 1976; Leader, 1977; Hopkinson, 1973; Tullet, 1965; Roberts J., Roberts R., 1977; Munro, 1977). Recentemente, isto recebeu o suporte de Skott (1978) que conclui que a "sintomatologia psiquiátrica (na parasitose delirante) é extremamente variada ... os pacientes podem sofrer de ilusões, equívocos e delírios e, em casos raros, de alucinações". A síndrome tem, portanto, se tornado independente da presença das alucinações táteis primárias.

\section{Classificação das alucinações táteis}

As alucinações táteis podem ser classificadas de acordo com critérios fenomenológicos ou clínicos. O primeiro é teoricamente importante na medida em que pode sugerir uma base descritiva para separar as alucinações dos delírios, por exemplo distinguindo a alucinação "pura" da "interpretada". Descrições de alucinações "puras" concentram-se na sensação em estado bruto, como as coceiras ou dores relatadas sem interpretação delirante. A existência clínica desses estados "puros", no entanto, é questionada pela visão de que uma vez que todas as 
alucinações são por definição distúrbios de percepção (e não de sensação), elas a fortiori incluem um componente cognitivo, interpretativo (Scharfetter, 1976). Em termos práticos, portanto, pode-se dizer que experiências alucinatórias "puras" não existem, e que as descritas como tal são alucinações com uma interpretação delirante "reduzida" ou "oculta".

Alucinações táteis, se associadas com psicoses funcionais, intoxicação por drogas, outros estados orgânicos e parasitoses delirantes tendem a ser encontradas na prática clínica, acompanhadas por evidentes e, muitas vezes, vívidas interpretações delirantes (por exemplo coceiras são relatadas como o rastejar de formigas). Dificuldades na separação em bases puramente fenomenológicas das coceiras "reais" das "ilusórias" ou "alucinadas" levaram certos autores a recorrer a uma avaliação aproximada da qualidade e extensão do delírio acompanhante (e do comportamento resultante) como um meio para o diagnóstico diferencial.

As classificações clínicas, por outro lado, são mais factuais, mas seu valor diagnóstico é igualmente duvidoso. Autores clássicos (por exemplo, Magnan, Saury, Clérambault) forneceram descrições detalhadas das alucinações táteis que acompanham diversos estados tóxicos e acreditavam que elas poderiam ser utilizadas para fins de diagnóstico. Não há evidência estatística que apoie essas ideias iniciais. Ey (1973) classificou as "alucinações hápticas" em "temáticas" e "atemáticas". Entre as primeiras, incluiu as alucinações de objetos "externos" (por exemplo, animais sobre a pele, contatos eróticos etc.) e objetos "internos", o melhor exemplo dos quais é a "zoopatia interna" (por exemplo, queixas de animais que vivem sob a pele ou dentro do corpo). Alucinações táteis "atemáticas" não têm objeto específico e descrevem primariamente sensações de tato, como pruridos, dores, cãibras, rupturas da pele, sensações de úmido, frio e calor. Ele também distinguiu duas "modalidades estruturais" nessas experiências: eidolie hallucinosiques e hallucinations délirantes tactiles (alucinações táteis delirantes). A primeira se refere a um grupo que inclui as pseudoalucinações, as alucinações localizadas orgânicas (acompanhadas por insight) e as experiências não delirantes alucinatórias. Esta última se refere a alucinações propriamente ditas em que o componente delirante (délire) constitui o núcleo mórbido, refletindo assim um grave deslocamento na relação entre o sujeito e seu mundo.

\section{Conclusões}

No início do século XIX, todos os tipos de "percepções sem objeto" foram reunidos por Esquirol sob a denominação comum de alucinações. Este termo tinha, até então, sido principalmente relacionado à visão, que é um "sentido de dis- 
tância". O modelo conceitual que gerou, portanto, era aplicável apenas para a audição, visão e, em menor medida, para o olfato e o paladar.

Uma série de experiências táteis alucinatórias permaneceram sempre fora das fronteiras epistemológicas do modelo convencional. Elas parecem ser fenômenos psicopatológicos sui generis que apenas superficialmente se assemelham a alucinações nos sentidos de distância.

O problema, portanto, é como elas são reconhecidas na prática clínica. Sugere-se que critérios tais como um acordo consensual sobre a ausência de estímulo público, a qualidade da percepção real mórbida, e a relação desta percepção ao campo contextual da percepção normal não são relevantes para o diagnóstico das alucinações táteis. Na verdade, esta análise sugere que esses três critérios (derivados do modelo causalista de percepção) não são relevantes para o reconhecimento de qualquer forma de alucinação.

Não se encontram disponíveis análises empíricas da árvore decisória a que aderem os médicos no diagnóstico das alucinações. Sobre as alucinações táteis conclui-se que na maioria das situações o componente delirante parece ser um importante fator diagnóstico, ou seja, fazer a avaliação aproximada da qualidade e intensidade do delírio e de sua influência sobre o comportamento.

Daí a possibilidade de os conceitos de alucinação e delírio poderem ser considerados, em geral, muito mais próximos uns dos outros do que até agora tem sido considerado na psiquiatria britânica, deve ser levada a sério. Esta parece ser, de fato, a posição tomada por um bom número de psiquiatras franceses, alemães e espanhóis.

\section{Referências}

Aristotle. De Anima, Books II and III. translated by Hamlyn, DW. Oxford: Clarendon Press, 1968.

Armstrong, D.M. Bodily sensations. London: Routledge and Kegan Paul, 1962.

Bergman, B. Zur Genese der taktilen Hallucinose bzw des Dermatozoenwahnes. Nervenarzt, n. 28, p. 22-27, 1957.

Bernard, P.; Trouve, S. Semiologie Psychiatrique. Paris: Masson et Cie, 1977. Berrios, G.E. Delirium and Confusion in the 19th century. Br J Psychiatry, n. 39, p. 439-449, 1981.

Berrios, G.E.; Brook, C.P. The Charles Bonnet Syndrome and the Problem of Visual Perceptual Disorders in the Elderly. Age and Ageing (in press), 1982. (Publicado neste número da revista, p. 542-562) 
Bers, N.; Conrad, K. Die chronische taktile Halluzinose. Fortsch Neurol, n. 22, p. 254$-270,1954$.

Bleuler, E. Dementia Praecox or the Group of the Schizophrenias. New York: International Universities Press, 1950.

Brierre de Boismont, A. Hallucinations. London: Henry Renshaw, 1859.

BRocQ, L. Quelques apercus sur les dermatoses prurigineuses. Ann Dermatol syphilig, n. 3, p. 1100, 1892.

Busch, G. Syndrom des wahnhaften Ungezieferbefalls beieinem Diabetiker. Z Gesamte Inn Med, n. 15, p. 411-417, 1960.

Claude, H.; Ey, H. Hallucinose et Hallucination. Encéphale, n. 27, p. 576-620, 1932.

Clerambault, G de. Oeuvre. Tome I, p. 145-210, 1909.

Condillac, E.B. de. Traité des sensations avec dissertation sur la liberté. Paris, 1754.

ConRad, K. Die beginnende Schizophrenie. Stuttgart: Thieme, 1958.

. "Die Symptomatischen Psychosen”. In: GruHLE, H.W. et al. (Herausgeg).

Psychiatrie der Gegenwart, Band II. Berlin: Springer-Verlag, 1960.

DARwin, E. Zoonomia. London: J. Johnson, 1796. 2 Vols.

Dupre, E. Les cenestopathies. Mouvement Medical, n. 23, p. 3-22, 1913.

Еквом, K.A. Der präsenile Dermatozoenwahn. Acta Psychiatry Neurol, n. 13, p. 227 $-259,1938$.

Esquirol, E. (1817). Hallucinations. Reprinted in Des Maladies Mentales. Paris: Baillière, 1938.

Ey, H. "Hypochondrie". Etude n.17. In: Etudes Psychiatriques. Paris: Desclée de Brouwer, 1950. V. 2. . Traité des Hallucinations. Paris: Masson et cie, 1973. V. 2.

Faure, H. et al. Sur les parasitoses delirantes. L'Evolution Psychiatrique, n. 22, p. 357- 375, 1957.

FLECK, U. Bemerkungen zur chronischen taktilen Halluzinose. Psychiat Z Neurol, n. 193, p. 261-276, 1955.

Freeman, W.; Williams, J.M. Hallucinations in Braille. Arch Neurol Psychiatry, n. 70, p. 630-634, 1953.

Gamper, E. Die Stellung des Zwischenhirns in psychozerebralen Apparat. Med Kin, n. 27 , p. $41-45,1931$.

Ganner, H.; Lorenzi, E. Der Dermatozoenwahn. Psychiat Clin, n. 8, p. 31-44, 1975.

Gautheret, F. Historique et position actuelle de la notion de schema corporel. Bull Psychol, n. 11, p. 41-44, 1961. 
Gordon, G. (Ed.). Active Touch. Oxford: Pergamon Press, 1978.

GrIeSINGER, W. Mental pathology and therapeutics. London: New Sydenham Society, 1867.

Hamilton, W Sir. Lectures on Logic and Metaphysics. Edinburgh: William Blackwood and Sons, 1859. 4 Vols.

Harbauer, H. Das Syndrom des "Dermatozoenwahns" (Ekbom). Nervenarzt, $\mathrm{n}$. 20, p. 254-258, 1949.

Hopkinson, G. The psychiatric syndrome of infestation. Psychiat Clin, n. 6, p. 330-345, 1973.

JASPERs, K. General Psychopathology. Manchester: University Press, 1963.

Johnson, F.H. The Anatomy of Hallucinations. Chicago: Nelson Hall, 1978.

Katz, D. Der Aufbau der Tastwelt. Z Psychol Physiol Sinnesorgane, suppl. II, 1925.

Keup, W. (Ed.). Origin and mechanisms of hallucinations. New York: Plenum Press, 1970.

Kraepelin, E. Dementia Praecox and Paraphrenia. Edinburgh: E and S Livingstone, 1919.

Ladee, G.A. Hypochondriacal syndromes. Amsterdam: Elsevier Publishing Co., 1966.

LEADER. Delusions of Parasitosis. Br Med, n. i, p. 790-791, 1977.

Levy, H. Les Delires de Zoopathie interne. Paris: These Steinheil, 1906.

Liebaldt, G.; Klages, W. Morphologische Befunde bei einer isolierten chronischen taktilen Dermatozoen-hallucinose. Nervenarzt, n. 37, p. 157-170, 1961.

LitTré, E. Dictionnaire de la langue Française. Paris: Librairie Hachette, 1878. V. 2.

Oxford English Dictionary: Compact Edition. Oxford University Press 1971.

Locke, J. An essay concerning human understanding. Fraser A.C., ed. New York:

Dover Publication, 1959.

Macnamara, E.D. Cutaneous and Visual Hallucinations. Lancet, n. i , p. 807-808, 1928.

Magnan, V.; SAURY, M. Trois cas de Cocainisme chronique. Comptes rendus,

Séances et Mem. Soc Bioi, p. 60-63, 1889.

MAIER, H.W. La cocaine. Paris: Payot, 1928.

Mallet, R.; Male, P. Délire cénesthesique. Ann Med Psychol, n. 88, p.198-201, 1930.

Merleau Ponty, M. La phenomenologie de la perception. Paris: Gallimard, 1945.

Moreau de Tours. Du Haschisch et de l'alienation mentale. Paris: Librairie de Poitiers 1845.

Mortimer, W.G. History of coca. San Francisco Press, 1974. 
Munro, A. Delusions of Parasitosis (Letter). Br Med J, n. i, p. 1219, 1977.

PARISH, E. Hallucinations and Illusions. London: Walter Scott, 1897.

PerRin, L. Des nevrodermies parasitophobiques. Ann dermatol syphilig, n. 7, p. 129$-138,1896$.

Porot, A. Manuel alphabétique de psychiatrie. Paris: Presses Universitaires de France, 1975.

Regis, E. Precis de Psychiatrie. Paris: Octave Doin, 1906.

ReILly, T.M.; BeARD, A.W. Monosymptomatic hypochondriasis (letter). $\mathrm{Br} J$ Psychiatry n. 129, p. 191, 1976.

Roberts, J.; Roberts, R. Delusions of Parasitosis (Letter). Br Med J, n. i, p. 1219, 1977. RoKhline, L.L. Les conceptions psychopathologiques de Kandinsky. L' Evolution Psychiatrique, n. 36, p. 475-488, 1971.

Scharfetter, C. Allegemeine Psychopathologie. Stuttgart: George Thieme Verlag, 1976.

Schwarz, H. Cirkumscripte Hypochondrien. Monatsschr Psychiat Neurol, n. 72, p. 150-164, 1929.

Siegel, R.K; West, U. (Eds.). Hallucinations: Behaviour, Experience and Theory. New York: John Wiley, 1975.

. Cocaine Hallucinations. Amer J Psychiatry, n. 135, p. 309-314, 1978.

Sigmond, G. On hallucinations. J Psychol Med Ment Pathol, n. 1, p. 585-608, 1848.

Sкотт, A. Delusions of Infestation. Reports from the psychiatric research center, St. Jörgen Hospital, University of Göteborg, Sweden, Gotab, Kungälv, 1978.

StÖRRING, G. Mental Pathology in its relation to normal psychology. London: Swan Sonnenschein and Co., 1907.

TAine, H. De L'intelligence. Paris: Librairie Hachette et Cie, 1890. V. 2.

Thiebierge, G. Les Acarophobes. Rev Gen de Clin et de thérapeutique, n. 32, p. 373, 1894.

Titchener, E.B. "Common sensation". In: Baldwin, J.W. (Ed.). Dictionary of Philosophy and Psychology. London: MacMillan, 1901. V. I.

. "Haptics". In: Baldwin, J.M. (Ed.). Dictionary of Philosophy and

Psychology. London: MacMillan, 1901. V. 1.

Tuke, D.H. Dictionary of Psychological Medicine. London: Churchill, 1892.

Tullet, G.L. Delusions of Parasitosis. Br J Dermatol, n. 77, p. 448, 1965.

WeBER, E.H. Der Tastsinn und das Gemeingefühl. In: Handwörterbuch der Physiologie, Vol. Ill, 1846.

West, L.J. (Ed.). Hallucinations. New York: Grune and Stratton, 1962. 
WiLson, J.W. Delusions of Parasitosis. Arch Dermatol Syph, n. 66, p. 577-585, 1952.

Wilson, J.W.; Miller, H.E. Delusions of Parasitosis. Arch Dermatol Syph, n. 54, p. 39-56, 1946.

Zienen, T. Introduction to Physiological Psychology. London: Swan Sonnenschein and Co., 1909.

\section{Resumos}

(Tactile hallucinations: conceptual and historical aspects)

A brief historical analysis of the general concept of hallucination is presented. The author suggests that this phenomenon appeared as an unjustified generalization of a model of perception that originally applied only to vision and the "senses of distance." The evolution of tactile hallucinations is discussed here, together with their interaction with 19th-century psychological theory. It can be concluded that tactile hallucinations are sui generis phenomena that do not fit into the conventional model and that today the identification of this clinical condition is based on very poorly specified criteria. A short review of the taxonomy and usefulness of this concept is presented and several broader implications are delineated, which may also be important for the general concept of hallucination.

Key words: Tactile hallucinations, psychopathology of touch, hallucinations - history, hallucinations - diagnosis

(Hallucinations tactiles: aspects conceptuels et historiques)

Cet article présente une brève analyse historique de la notion générale de l'hallucination et suggère qu'il s'agit d'une généralisation injustifiée d'un modèle perceptif qui était destiné à s'appliquer uniquement à la vision et aux "ens de la distance". Dans ce contexte, nous analysons l'évolution des hallucinations tactiles et explorons son interaction avec la théorie psychologique du XIXe siècle. Nous concluons que les hallucinations tactiles sont des phénomènes sui generis qui ne correspondent pas au modèle conventionnel et que l'identification de leur cadre clinique se base, jusqu'à présent, sur de des critères peu claires. Cet article présente une brève révision de sa taxonomie et de son utilité diagnostique. Certaines implications plus amples sont décrites qui pourraient être pertinentes pour le concept général de l'hallucination.

Mots clés: Hallucinations tactiles, psychopathologie du toucher, hallucinations - histoire, hallucinations - diagnostic 


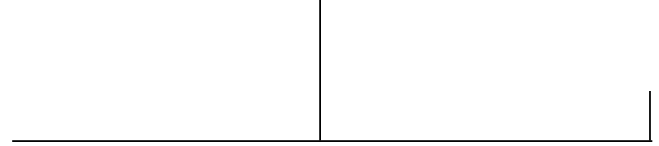

(Alucinaciones táctiles: aspectos conceptuales e históricos)

Se presenta un breve análisis histórico del concepto general de alucinación y se sugiere que ese concepto general surgió como una generalización injustificada de un modelo perceptivo que estaba destinado a ser aplicado apenas a la visión y a los "sentidos de distancia”. Dentro de este contexto, se examina la evolución de las alucinaciones táctiles así como también se explora sus interacciones con la teoria psicológica vigente en el siglo XIX. Se concluye que las alucinaciones táctiles son fenómenos sui géneris, que no se ajustan al modelo convencional y que la identificación de su cuadro clínico se basa, hasta el momento, en criterios poco claros. Se presenta, también, una breve revisión de su taxonomia y de su utilidad diagnóstica. Son delineadas algunas implicaciones más amplias que pueden ser relevantes para una concepción general de la alucinación.

Palabras clave: Alucinaciones táctiles, psicopatologia del tacto, alucinaciones - historia, alucinaciones - diagnóstico

Citação/Citation: BERRIos, G.E. Alucinações táteis: aspectos conceituais e históricos. Revista Latinoamericana de Psicopatologia Fundamental, São Paulo, v. 14, n. 3, p. 542-562, set.2011.

Editor do artigo/Editor: Prof. Dr. Manoel Tosta Berlinck

Recebido/Received: 15.7.2010 / 7.15.2010 Aceito/Accepted: 25.9.2010 / 9.25.2010

Copyright: @ 2009 Associação Universitária de Pesquisa em Psicopatologia Fundamental/ University Association for Research in Fundamental Psychopathology. Este é um artigo de livre acesso, que permite uso irrestrito, distribuição e reprodução em qualquer meio, desde que o autor e a fonte sejam citados/This is an open-access article, which permits unrestricted use, distribution, and reproduction in any medium, provided the original author and source are credited.

Rev. Latinoam. Psicopat. Fund., São Paulo, v. 14, n. 3, p. 542-562, setembro 2011 
Financiamento/Funding: $\mathrm{O}$ autor declara não ter sido financiado ou apoiado/The author has no support or funding to report.

Conflito de interesses/Conflict of interest: $O$ autor declara que não há conflito de interesses/The author declares that has no conflict of interest.

\section{German E. Berrios}

Médico e filósofo pela Universidad Nacional de San Marcos, Lima, Peru; Psiquiatra; Neurologista; Psicólogo; Filósofo; Historiador e Filósofo da ciência (Oxford University, England); Professor de Neuropsiquiatria e de Epistemologia da Psiquiatria (University of Cambridge, England), desde 1976; Neuropsiquiatra e Chefe do Departamento de Neuropsiquiatria do Hospital Addenbrooke, University of Cambridge, por 32 anos; Coordenador do Comitê de Ética em Pesquisa com Humanos na mesma universidade, por 20 anos; Editor Responsável de History of Psychiatry; Autor de 14 livros, incluindo The History of Mental Symptoms, Descriptive Psychopathology since 19th Century (Prêmio Nacional BMA, 1997), A History of Clinical Psychiatry (com Roy Porter), e Delirio (com F. Fuentenebro) e mais de 400 artigos e capítulos de livros; Membro do Royal College of Psychiatrists; da Associação Britânica de Psicologia e da Academia Britânica de Ciências Médicas; Membro Vitalício do Robinson College, Cambridge; doutor Honoris-Causa da Universidade de Heidelberg (Alemanha), da Universidade Nacional Mayor de San Marcos (Peru) e da Universidad Autónoma de Barcelona (Espanha); Grão Oficial da Ordem del Sol (Condecoração do Governo Peruano, 2007); prêmio Ramon y Cajal 2008 concedido pela Asociación Internacional de Neuropsiquiatria.

University of Cambridge

Box 189, Hills Road

Cambridge,

UK CB2 2QQ

e-mail: geb11@cam.ac.uk 